\title{
Do Consumption Tax Cuts Lead to Dynamic Laffer Effects in Open Economies?
}

\author{
Wenchun Wang1, Yang Wang 1 , Jiaojiao Wang ${ }^{2}$ \\ ${ }^{1}$ Financial Research Center, Fudan University, Shanghai, China \\ ${ }^{2}$ School of Economics, Fudan University, Shanghai, China \\ Email: wangwc@fudan.edu.cn, milanwgy@163.com,wangjiaoj@missouri.edu
}

How to cite this paper: Wang, W.C., Wang, Y. and Wang, J.J. (2017) Do Consumption Tax Cuts Lead to Dynamic Laffer Effects in Open Economies? Theoretical Economics Letters, 7, 324-338.

https://doi.org/10.4236/tel.2017.73025

Received: February 15, 2017

Accepted: March 13, 2017

Published: March 16, 2017

Copyright ( 92017 by authors and Scientific Research Publishing Inc. This work is licensed under the Creative Commons Attribution International License (CC BY 4.0).

http://creativecommons.org/licenses/by/4.0/

cc) (i) Open Access

\begin{abstract}
This paper extends benchmark OR model with consumption tax reform, based on "New open economy macroeconomics" framework, and analyzes responses of consumption tax reduction to output, consumption, exchange rate. Our analytical results show that a unilateral cut in consumption tax rate for domestic country results in a domestic depreciation, generates a domestic boom in which both output and consumption increase in the short-run and longrun. We focus on the dynamic Laffer effects to happen by numerical solutions from our derived analytical solutions, in the sense that it has positive budgetary consequences for the country which implements it. So both government and residents can get benefits from a consumption tax cut.
\end{abstract}

\section{Keywords}

Dynamic Laffer Effects, Consumption Tax, New Open Economy

Macroeconomics, Nominal Revenue Collection, Real Revenue Collection

\section{Introduction}

A consumption tax is a tax on spending on goods and services. With the Bush tax cuts in the US from 2001 due to expire soon and debates about raising tax rates further to cut the US government deficit soon to follow, the effect of consumption tax reform is coming up again not only in public but also in academic discussions. What are the implications of consumption tax reform for macroeconomic and government budgetary consequences? The model presented in this paper extends OR model to incorporate consumption tax so as to analyze this question.

The Laffer curve is a representation of the relationship between rates of taxation and the resulting levels of government revenue. Proponents of the Laffer curve claim that it illustrates the concept of taxable income elasticity. The original idea for the Laffer curve is a hump-shaped relationship between government 
revenues raised by taxation and all possible ranges of taxation rate. Furthermore, much of academic excellences have extended this concept in a dynamic scoring. The core view for dynamic Laffer curve (or effects) to happen is that tax cuts today will increase economic growth and generate more tax revenues in the future. But most of the studies are based on the endogenous growth model.

Ireland [1] shows that in a simple convex model of endogenous growth, the expansionary effects of a deficit-financed tax cut are strong enough to pay off the government debt in the long run. A permanent reduction in marginal rates of income tax can provide for both real economic growth and long-run government budget balance which implies the existence of dynamic Laffer effects. However, Mendoza [2] examines the grow effects of tax policy in the class of endogenous grow models driven by human capital accumulation. The numerical simulations results confirm inexistence of dynamic Laffer effects. Novales and Ruiz [3] also use an endogenous growth model with human capital accumulation. They show that dynamic Laffer effects can arise given by initial income tax rate of 23 percent. Bruce and Turnovsky [4] believe that the dynamic Laffer effects can never happen if intertemporal elasticity of substitution is lower than unity. All of this literature above is under closed-economy endogenous growth models to study this issue. However, Mankiw and Weinzierl [5], Trabandt and Uhlig [6] believe that, due to the necessity of growth impact of tax cuts in endogenous growth models, it has more sense to put this issue in neoclassical Real Business Cycle (RBC) framework to observe how much tax cut pays for itself. The larger value the degree of self-financing is, the lower possible the dynamic Laffer effects emerge. They find that the degree of self-financing for income tax is 17 percent using standard calibrated parameter values, which means lower possible of the dynamic Laffer effects.

Ganelli and Tervala [7] also stress that the dynamic Laffer effects are likely to emerge in endogenous growth model models above due to the fact that the growth impact of tax cuts are so large to offset all of losses for government taxation revenue today under the assumption of endogenous growth. So they use numerical simulation methods to show that under the NOEM framework, both income and consumption unilateral tax rate reductions have resulted in negative budgetary consequences for the country which implement them. Their results have important implications for the study of the dynamic Laffer effects under open economic dimension contrary to closed-economy dimension.

This paper takes consumption tax reforms in open economies for example to study dynamic Laffer effects using two-country sticky-price "New Open Economy Macroeconomic"(NOEM) paradigm developed by Obstfeld and Rogoff [8] $[9]^{1}$. This allows us to take into account the impact of a tax cut not only on the long-run equilibrium but also on the short-run in which output is demand determined stemming from the presence of nominal rigidities, as well as macroe-

\footnotetext{
${ }^{1}$ An open economy is an economy in which there are economic activities between the domestic community and outside. People and even businesses can trade in goods and services with other people and businesses in the international community, and funds can flow as investments across the border.
} 
conomic dynamic effects. To the best of our knowledge, the only paper that has so far studied the macroeconomic and budgetary implication of tax reform under NOEM paradigm is contributed by Ganelli and Tervala [7]. The main contribution from their paper in our exercise is that we can derive analytical solutions, and use a simple graphical apparatus, which can give us an intuitive explanation, to illustrate our issue rather than numerical simulation applied by them. Since we can gain analytical solutions, it allows us to evaluate the changes of total revenue collections more rigorously using numerical solution. More importantly, contrary to their exercise, which consumption tax cuts have a negative effect on budgetary consequence, our results show that consumption tax cuts yield dynamic Laffer effects. Our exercise of consumption tax cuts in this paper deriving the fact opposed from their numerical experiment that dynamic Laffer effects emerge in open economies is interesting results. We also hope that this paper associated with their paper can stimulate further research for dynamic Laffer effects under the NOEM framework.

The paper proceeds as follows: next section describes the model in detail; Section 3 discusses the effects of a cut in consumption tax rate; Section 4 focuses on budgetary impact of tax cut; Section 5 concludes.

\section{The Model}

The model presented in this section is an extention of OR [8] [9]. There are two countries in the world, which we label Home and Foreign. The world is populated by a continuum of infinitely-lived agents. Every agent being both household and firm is indexed by $z \in[0,1]$. Home agents are located in the interval $[0, n]$, while foreign agents are on the interval $(n, 1]$. Total world population is normalized to 1 . In this paper we restrict our attention to producer currency pricing (PCP) just as OR model. In the presentation of the model below we will introduce domestic equations. Due to the symmetry of the model, the foreign agents can be assumed to be analogous to domestic equations. So we will mainly present the optimization problem of the domestic agent. We use notation "*” to denote foreign variables.

\subsection{The Representative Agent}

Agents can derive utility from consumption of a composite good, leisure and real balances. Agents supply labor in the perfectly competitive labor market, receive shares of profits from firms and real transfer from the government.

The domestic agent's optimization problem can therefore be interpreted as

$$
U_{t}=\sum_{s=t}^{\infty} \beta^{s-t}\left[\log C_{s}+\chi \log \frac{M_{s}}{P_{s}}-\frac{k}{2} l_{s}^{2}(z)\right]
$$

Subject to the budget constraint

$$
M_{t}+P_{t} B_{t+1}=P_{t}\left(1+r_{t}\right) B_{t}+M_{t-1}+w_{t} l_{t}(z)-\tau_{t}^{C} P_{t} C_{t}+\pi_{t}+P_{t} T_{t}
$$

where the subscript $\mathrm{t}$ refers to time, $0 \prec \beta \prec 1$ is discount factor, $\chi$ and $\kappa$ 
positive parameters. $\mathrm{C}$ is a composite good and representing consumption and $\mathrm{P}$ is the price index together with it. $l(z)$ is the household's supply of labor for good $\mathrm{z}$. The only asset they trade is a nominal bond denominated in the currency of the domestic country, that we denote with $D . i_{t}$ is the nominal interest rate on this bond between $t$ and $t+1 . M_{t-1}$ denotes nominal money balances held at the beginning of period t. $w_{t}$ is the nominal wage paid to the household in a competitive labor market. $\pi_{t}$ is the household's share of profits from domestic firms. $T_{t}$ denotes real transfer from the government. $\tau_{t}^{C}$ is a consumption tax included in price, and thus $\tau_{t}^{C}-1$ denotes tax rate on household's consumption. We have $\tau_{t}^{C} \geq 1$. The government implements the consumption tax cut if $\tau_{t}^{C}$ decreases. Obviously, our setup reduce to OR model when $\tau_{t}^{C}=1$, which means the government doesn't deliver consumption tax on households ${ }^{2}$.

Let $c(z)$ be a home individual's consumption of product $z$. The consumption index is given by

$$
C=\left[\int_{0}^{1}(c(z))^{\frac{\theta-1}{\theta}}\right]^{\frac{\theta}{\theta-1}}
$$

where $\theta \succ 1$ is the elasticity of substitution between any pair of individual goods. The corresponding price index is

$$
P=\left[\int_{0}^{n} p(z)^{1-\theta} \mathrm{d} z+\int_{n}^{1}\left(e p^{*}(z)\right)^{1-\theta}\right]^{\frac{1}{1-\theta}}
$$

where $p(z)$ is the price of good $\mathrm{z}$ denominated by domestic currency, $p^{*}(z)$ is the foreign currency price of foreign good $\mathrm{z}$ and $\mathrm{e}$ is the nominal exchange rate which is defined as the price of the foreign currency in terms of the domestic currency. We assume that the law of one price holds. This implies that the home and foreign consumer prices indexes are linked by the purchasing power parity (PPP) relationship $P=P^{*} E$.

Solving the optimization problem presented above yields the following firstorder conditions:

$$
\begin{gathered}
C_{t+1}=\beta \frac{\tau_{t}^{C}}{\tau_{t+1}^{C}}\left(1+r_{t+1}\right) C_{t} \\
k l_{t}(z)=\frac{w_{t}}{\tau_{t}^{C} P_{t} C_{t}} \\
\frac{M_{t}}{P_{t}}=\chi \tau_{t}^{C} C_{t} \frac{1+i_{t+1}}{i_{t+1}}
\end{gathered}
$$

Equation (5) is the Euler equation for optimal domestic consumption including consumption tax. Equation (6) is labor-leisure trade-off equation, which equates the marginal disutility of labor with the marginal utility of the consumption. Equation (6) shows that higher consumption tax lower labor supply for given by levels of the real wage and consumption. Equation (7) equates the mar-

${ }^{2}$ Such setup is available for tractability reasons. 
ginal utility of real balances to the opportunity cost in terms of consumption, which money demand is a positive relation with consumption tax.

\subsection{Firms}

For simplicity it is assumed that output is equal to labor input. Thus

$$
y_{t}(z)=l_{t}(z)
$$

where $y(z)$ is output of firm $z$. We also assume that each firm enjoys a certain degree of monopolistic power in the production of its differentiated good. Under this assumption, demand for the output of firm $z$ is given by

$$
y_{t}^{d}(z)=\left(\frac{p_{t}(z)}{P_{t}}\right)^{-\theta} C_{t}^{w}
$$

where $C_{t}^{w}$ denotes world aggregate consumption given by $C_{t}^{w}=n C_{t}+(1-n) C_{t}^{*}$. In the absence of price rigidities, the profit maximization process would imply that the price of each differentiated good is given by a simple mark-up over wages, according to the equation

$$
p_{t}(z)=\frac{\theta}{\theta-1} w_{t}
$$

\subsection{Government}

It is assumed that there is no government spending and real transfer to households can be financed through consumption tax or seignorage $e^{3}$. The government budget constraint, expressed in per-capita terms, is given by

$$
T_{t}=\frac{M_{t}-M_{t-1}}{P_{t}}+\left(\tau_{t}^{C}-1\right) C_{t}
$$

\subsection{The Initial Steady State}

We consider an initial steady state where net foreign assets are zero for both countries $\left(D_{0}=D_{0}^{*}=0\right)$. Under this assumption we have, applying the zero subscript to denote the initial steady state:

$$
C_{0}=y_{0}=\sqrt{\frac{1}{k \tau_{0}^{C}} \frac{\theta-1}{\theta}}
$$

\subsection{Short-Run Nominal Rigidities and Log-Linearization}

We also introduce short-run nominal rigidities in the form of one period preset prices in the currency of the producer as in OR model. In terms of notation, in the log-linearized version of the model, we will denote short-run variables using tildes, and long-run variables using hats. In the short run, nominal producer prices $\tilde{p}(h)$ and $\tilde{p}^{*}(f)$ are predetermined; that is, they are set a period in advance but can be adjusted fully after one period.

In order to solve our model, we should resort to log-linearization. Table 1 summarizes the log-linearization of the model around the initial steady state ${ }^{3}$ In what follows we keep money supply constant, therefore abstracting from seignorage in practice. 
Table 1. Summarizes the log-linearization of the model around the initial steady state presented above.

$$
\begin{gathered}
\tilde{P}=n \tilde{p}(h)+(1-n)\left(\tilde{e}+\tilde{p}^{*}(f)\right) \\
\hat{C}=\tilde{C}+\frac{\delta}{1+\delta} \tilde{r} \\
\tilde{M}-\tilde{P}=\tilde{C}-\frac{\tilde{r}}{1+\delta}-\frac{\hat{P}-\tilde{P}}{\delta}+\hat{\tau}^{C} \\
\hat{P}=\hat{M}-\hat{C}-\hat{\tau}^{C} \\
\hat{y}=\hat{p}(h)-\hat{P}-\hat{C}-\hat{\tau}^{c} \\
\tilde{y}=-\theta(\tilde{p}(h)-\tilde{P})+\tilde{C}^{w} \\
\hat{D}=\tilde{y}-\tilde{C}-(1-n) \tilde{e} \\
\hat{C}=\delta \hat{D}+\hat{p}(h)-\hat{P}+\hat{y} \\
\tilde{e}=\tilde{P}-\tilde{P}^{*} \\
\tilde{y}^{w}=\tilde{C}^{w}=-\hat{\tau}^{c, w} \\
\hat{y}^{w}=\hat{C}^{w}=-\frac{1}{2} \hat{\tau}^{c, w}
\end{gathered}
$$

Note: Home real interest rate are given by Fisher equation $1+r_{t+1}=\frac{P_{t}}{P_{t+1}}\left(1+i_{t+1}\right) ; \delta \equiv i_{0}=\frac{1-\beta}{\beta}$ is initial steady-state interest rate; We define $\hat{\tau}^{c, w} \equiv n \hat{\tau}^{c}+(1-n) \hat{\tau}^{\circ c}$.

presented above ${ }^{4}$.

Due to the symmetry of the model, only the domestic equations, the PPP equation, and the world goods market equilibrium equation are reported. Equations ((13) to (23)) are log-linearized versions of price index, the Euler equation, the short-and long-run money demand equations, the labor-leisure supply equation, the demand equation, the short-and long-run current account equations, the PPP equation and the short-and long-run world goods market equilibrium condition.

\section{Effects of a Cut in Consumption Tax Rate}

In this section we look at the domestic and international macroeconomic effects under a reduction in consumption tax rate.

\subsection{Two Basic Relationships of the Model}

In order to observe the effects of the policy of a reduction in consumption tax rate, it is useful to combine the various equations so as to obtain two basic relationships, which can provide a simple and intuitive graphical solution of the model.

Combining the PPP equation, the Euler equation, the money demand equation, and their foreign counterparts, we can derive the below relationship be${ }^{4}$ For simplicity, in what follows we assume the policy of permanent consumption tax rate cuts (i.e. $\hat{\tau}^{C}=\tilde{\tau}^{C}$ ), so log-linearized version of consumption Euler equation reduces to Equation (14) from $\hat{C}=\tilde{C}+\frac{\delta}{1+\delta} \tilde{r}+\tilde{\tau}^{C}-\hat{\tau}^{C}$. 
tween short-run relative consumption and the nominal exchange rate:

$$
\tilde{e}=-\left(\tilde{C}-\tilde{C}^{*}\right)-\left(\hat{\tau}^{C}-\hat{\tau}^{*}\right)
$$

Equation (24) is similar to "MM" curve in OR model. It expresses the fact that an increase in domestic consumption with respect to foreign, by increasing money demand for a given level of the money supply, requires an appreciation of the domestic currency (a decrease in $\tilde{e}$ ) so as to keep equilibrium in the money market. We also refer this mechanism to as the "money demand" effect just like Ganelli [10] [11].

Combining the other equations of the model can follow a second relationship between the nominal exchange rate and relative consumption. In detail, combining the domestic and foreign long-run demand equations and current account equations as well as labor-leisure supply equations, we can derive the following equation:

$$
\hat{D}=\frac{2 \theta(1-n)}{\delta(1+\theta)}\left[\left(\hat{C}-\hat{C}^{*}\right)+\frac{\theta-1}{2 \theta}\left(\hat{\tau}^{C}-\hat{\tau}^{* C}\right)\right]
$$

In order to eliminate $\hat{D}$ we can apply the short-run current account equations. Subtracting from Equation (20) its foreign counterpart and using the fact that the hypothesis of one period prices rigidities and domestic and foreign demand equations imply $\tilde{y}-\tilde{y}^{*}=\theta \tilde{e}$, we get:

$$
\hat{D}=(1-n)\left[(\theta-1) \tilde{e}-\left(\tilde{C}-\tilde{C}^{*}\right)\right]
$$

Combining Euler equation (14) and its foreign counterpart it can be easily shown that relative consumption follows a unit root process (i.e. $\hat{C}-\hat{C}^{*}=\tilde{C}-\tilde{C}^{*}$ ) just as OR model. Combining Equation (25) with Equation (26), and making use of the "unit root" result we can eliminate $\hat{D}$ and get a second relationship between nominal exchange rate and relative consumption which is similar to the one called "GG" curve in OR model.

$$
\tilde{e}=\frac{\delta(1+\theta)+2 \theta}{\delta\left(\theta^{2}-1\right)}\left(\tilde{C}-\tilde{C}^{*}\right)+\frac{1}{\delta(1+\theta)}\left(\hat{\tau}^{C}-\hat{\tau}^{* C}\right)
$$

Obviously, Equation (27) presents a positive relationship between $\tilde{e}$ and $\tilde{C}-\tilde{C}^{*}$. Equation (27) describes another mechanism at work in the model, which goes in the opposite direction contrasted to the "money demand" effect. From Equation (26) we can know the fact that an increase of relative consumption worsens the domestic current account, thus putting a pressure for depreciation of the domestic currency (an increase in $\tilde{e}$ ). We can call this mechanism as "current account" effect.

Figure 1 describes a graphical representation of Equations ((24) and (27)) for no consumption tax policy (i.e. $\hat{\tau}^{C}=\hat{\tau}^{* C}=0$ ). The intuition for the downward sloping shape of Equation (24) is "money demand" effect, which we have just mentioned, while "current account" effect implies the upward sloping shape of Equation (27). This graphical apparatus will be useful in what follows in order to provide some intuition for the macroeconomic effects of the policy changes 


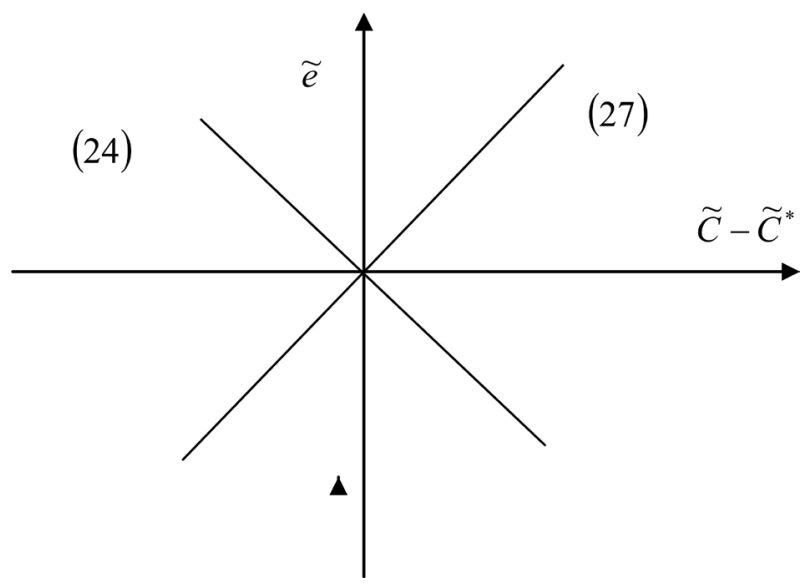

Figure 1. A graphical representation of Equations ((24) and (27)) for no consumption tax policy.

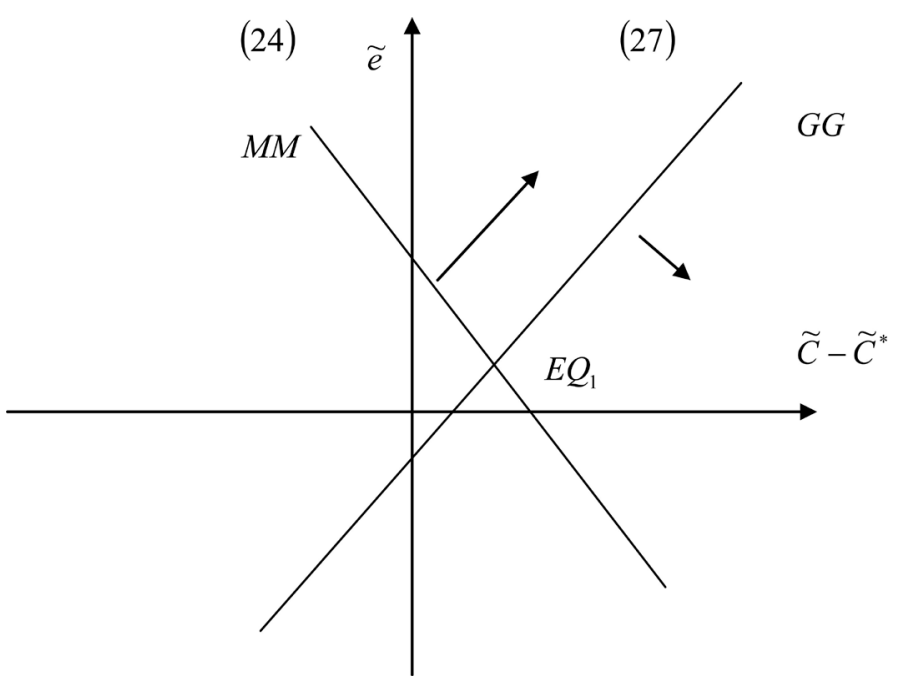

Figure 2. The effects of a cut in domestic consumption tax rate compared to foreign.

which we are considering.

\subsection{Comparing Cuts in Consumption Tax}

Figure 2 illustrates the effects of a cut in domestic consumption tax rate compared to foreign (i.e. an decrease in $\hat{\tau}^{C}-\hat{\tau}^{* C}$ ).

An asymmetric reduction in domestic consumption tax rate relative to foreign ( $\hat{\tau}^{C}-\hat{\tau}^{* C} \prec 0$ ) implies a higher level of $\tilde{e}$ (a domestic depreciation) for any given relative consumption $\left(\tilde{C}-\tilde{C}^{*}\right)$ according to the graphical terms, and this policy moves Equation (24) upward while Equation (27) rightward (see Figure 2). The new equilibrium will arrive at the new intersection point EQ1 compared to original point in Figure 2. This shows that the level of relative consumption will be higher while the level of nominal exchange rate will be higher.

The intuition for the result that domestic consumption increases more compared to the foreign consumption is obviously due to the fact that domestic agents get lower consumption tax rate than its foreign counterparts. The depreciation of domestic currency is due to "money demand" effect as follows: Since 
money demand is a positive relation with consumption including taxes, cuts in consumption tax rate has a negative effect on domestic money demand, which is stronger than the effect of the increase in real consumption excluding taxes due to our parameterization. As a result, the fact that domestic consumption increases more relative to the foreign consumption raises domestic currency demand, but an asymmetric reduction in domestic consumption tax rate relative to foreign reduces domestic currency demand more. Finally, domestic currency demand is decrease associated with domestic depreciate so as to restore equilibrium in the money market.

Because of $\tilde{y}-\tilde{y}^{*}=\theta \tilde{e}$, we can conclude that the depreciation of the nominal exchange rate also means a increase in domestic output relative to foreign. The expenditure switching effect is at work, which shifts demand from foreign goods to domestic goods due to the fact that the prices of foreign goods become cheaper in the presentation of the depreciation of the domestic currency and the short-run price rigidities.

\subsection{Long-Run Effects}

Starting by the "unit root" result $\left(\hat{C}-\hat{C}^{*}=\tilde{C}-\tilde{C}^{*}\right)$, we can know that the effect of the policy changes on relative consumption in the long-run will be the same as in the short-run. A cut in domestic consumption tax rate compared to foreign thus implies an increase in domestic consumption relative to foreign both in the short run and in the long run.

So as to better figure out the long-run mechanism of this policy, it is valuable to get its effect on the long-run net foreign asset position of the domestic country $\hat{D}$. After combining Equations $((24)$ and $(27))$ in order to denote $\tilde{C}-\tilde{C}^{*}$ as a function of policy variables only, we apply the "unit root" result to find an expression which can be used to eliminate $\hat{C}-\hat{C}^{*}$ in Equation (25), generating the following reduced form for $\hat{D}$

$$
\hat{D}=-\frac{(1-n)(\theta-1)}{\delta(1+\theta)+2}\left(\hat{\tau}^{C}-\hat{\tau}^{* C}\right)
$$

Since the coefficient on right-hand sides in Equation (28) is negative, a cut in domestic consumption tax rate compared to foreign (i.e. $\hat{\tau}^{C}-\hat{\tau}^{*} C \prec$ ) has a positive effect on the net foreign asset of the domestic country.

The intuition for this result is due to the increase in relative consumption in the short run associated with the short-run increase in relative output, but the latter dominates the upper, so domestic households will increase long-run financial position relative to its foreign counterparts.

In order to observe the influence on long-run output, we combine the labor-leisure supply Equation (17), the demand Equation (18), the long-run current account Equation (20) with their foreign counterparts, and it yields:

$$
\hat{y}-\hat{y}^{*}=-\frac{1}{2(1-n)} \delta \hat{D}-\frac{1}{2}\left(\hat{\tau}^{C}-\hat{\tau}^{* C}\right)
$$

On the one hand, the negative proportion between $\hat{y}-\hat{y}^{*}$ and $\hat{D}$ explains 
the fact that the wealth transfer associated with a net foreign asset position enables home residents to work less, and consume more than their foreign counterparts, which it means that "current account" effect is at work. As a result, a cut in domestic consumption tax rate compared to foreign which increase net foreign asset position of domestic country from Equation (28) will decrease relative long-run output of both countries. On the other hand, a cut in domestic consumption tax rate compared to foreign (i.e. $\hat{\tau}^{C}-\hat{\tau}^{*} \prec 0$ ) increases $\hat{y}-\hat{y}^{*}$ according to the second term on the right-hand side in above equation. The intuition behind the result is that a cut in domestic consumption tax rate compared to foreign increases the opportunity cost of leisure for domestic agents relative to foreign counterparts, so this pushes domestic agents to decrease their long-run leisure in contrast with foreign, in the sense that domestic agents increase their long-run output with respect to foreign agents. Furthermore, we combine Equations ((28) and (29)) to derive analytical expression of relative output in the long run

$$
\hat{y}-\hat{y}^{*}=-\frac{1+\delta}{\delta(1+\theta)+2}\left(\hat{\tau}^{C}-\hat{\tau}^{* C}\right)
$$

Obviously, from this result we can conclude that the latter mechanism dominates the "current account" effect, so the policy of consumption tax cuts increase relative long-run output of both countries.

It is well known that a in a two-country model like the one we are presenting the level of a generic domestic variables can be decomposed as follows:

$x=x^{w}+(1-n)\left(x-x^{*}\right)$, so we can easily derive analytical solutions of domestic consumption and output both in the short run and in the long run in order to analyze the response of a reduction in domestic consumption tax rate to both nominal and real revenue collection in the next section. Those results are reported in Table 2, where analytical solutions of nominal exchange rate (35) derive from combining Equations ((24) and (27)).

From Table 2 we easily know that a unilateral cut in consumption tax rate for domestic country (i.e. $\hat{\tau}^{C} \prec 0$ and $\hat{\tau}^{* C}=0$ ) yields a domestic boom, since the

Table 2. Summarizes analytical solutions of domestic variables.

$$
\begin{gathered}
\tilde{y}=-\frac{(1-n) \theta+\delta(\theta+1)+1+n}{\delta(1+\theta)+2} \hat{\tau}^{C}-\frac{(1-n)[2+(\theta+1)(1+2 \delta)]}{\delta(1+\theta)+2} \hat{\tau}^{*^{C} C} \\
\tilde{C}=-\left\{n+\frac{(1-n)(\theta-1)}{2 \theta+\delta(1+\theta)}\left[1+\frac{\delta(\theta+1)^{2}(1+\delta)}{\theta \delta(1+\theta)+2 \theta}\right]\right\} \hat{\tau}^{C}-\frac{(1-n)(1+\delta)(\theta+1)}{[\theta \delta(1+\theta)+2 \theta]} \hat{\tau}^{*^{C} C} \\
\hat{y}=-\frac{2 \delta+2+n \delta(\theta-1)}{2[\delta(1+\theta)+2]} \hat{\tau}^{C}-\frac{1}{2}(1-n) \frac{\delta(\theta-1)}{\delta(1+\theta)+2} \hat{\tau}^{* C} \\
\hat{C}=-\left[\frac{1}{2} n+(1-n) \frac{(\theta-1)[(\delta(1+\theta))+1]}{\theta(\delta(1+\theta)+2)}\right] \hat{\tau}^{C}-\frac{1-n}{2 \theta}\left[\frac{\theta \delta(\theta-1)-2(\delta+1)}{\delta(1+\theta)+2}\right] \hat{\tau}^{* C} \\
\tilde{e}=\hat{e}=-\frac{(\theta+1)(1+\delta)}{\theta \delta(1+\theta)+2 \theta}\left(\hat{\tau}^{C}-\hat{\tau}^{* C}\right)
\end{gathered}
$$


policy increases domestic consumption and output not only in the short run but also in the long run, makes domestic currency depreciate(i.e. nominal exchange rate increases).

\section{Does Consumption Tax Rate Reduction Lead to the Dynamic Laffer Effects?}

In the section we estimate the response of a unilateral cut in consumption tax rate for domestic country to both domestic nominal and real revenue collection both in the short run and in the long run. For simplicity we also assume that government can only deliver two kinds of taxations: income tax and consumption tax, which follow Ganelli and Tervala [7] setup.

\subsection{Nominal Revenue Collection (NRC)}

$$
\begin{aligned}
& \overparen{N R C} \equiv u\left(\hat{\tau}^{I}+\tilde{w}+\tilde{l}\right)+(1-u)\left(\hat{\tau}^{C}+\tilde{C}+\tilde{P}\right) \\
& \widehat{N R C} \equiv u\left(\hat{\tau}^{I}+\hat{w}+\hat{l}\right)+(1-u)\left(\hat{\tau}^{C}+\hat{C}+\hat{P}\right)
\end{aligned}
$$

where the definition of the short-run and long-run NRC can derive from households budgetary constraint Equation (2), $\hat{\tau}^{I}$ denotes changes in income tax rate in the spirit of setup of $\hat{\tau}^{C}$. $\mathrm{u}$ is the share of income tax on total taxes and $1-\mathrm{u}$ is the proportional of consumption tax on total taxes in the initial steady state. Equations ((36) and (37)) present the changes of total nominal revenue collection for government both in the short and long run.

In the short run, we can easily know that $\tilde{w}=\tilde{p}(z)=0$ due to both price rigidity and Equation (10), $\tilde{l}=\tilde{y}$ from Equation (8). We also can derive $\tilde{P}=(1-n) \tilde{e}$ using the hypothesis of one period price stickiness in price index Equation (13). In the long run, $\hat{w}=\hat{p}(z)=\hat{P}$ holds due to the symmetric steady state, and from the long-run money demand Equation (16) we can derive $\hat{P}=-\hat{C}-\hat{\tau}^{C}$. Since we restrict the attention to a reduction in consumption tax rate, there is no income tax impact (i.e. $\left.\hat{\tau}^{I}=0\right)$. Finally, we can derive reduced form for both Equations ((36) and (37)) respectively:

$$
\begin{gathered}
\widehat{N R C}=u \tilde{y}+(1-u)\left(\hat{\tau}^{C}+\tilde{C}+(1-n) \tilde{e}\right) \\
\widehat{N R C}=u\left(-\hat{C}-\hat{\tau}^{C}+\hat{y}\right)
\end{gathered}
$$

In order to derive analytical expressions for both short-run and long-run NRC, we substitute Equations ((31), (32) and (35) into (38)), while plugging Equations ((33) and (34) into (39)), yielding the reduced form only including policy variable $\hat{\tau}^{C}$ (because we have already assumed the foreign consumption tax at unchanged level, $\hat{\tau}^{* C}=0$ ) for $\overparen{N R C}$ and $\widehat{N R C}$. However, due to the complexity of parameter expressions of coefficients in above both reduced-form equations only including policy variable $\hat{\tau}^{C}$, it is not straightforward to tell coefficient signs on right-hand sides in two RRC equations above, so we resort to numerical solutions using calibrated parameters as follows. In order to compare with the numerical simulation result of Ganelli and Tervala [7], we also follow 
the benchmark parameters applied their paper. The elasticity of substitution between differentiated goods $\theta$ is equal to 11 . The discount factor $\beta$ is set to 0.94 , which means a steady-state interest rate of about 6 percent (i.e. $\delta=0.06$ ). The scale of both countries is assumed to be of equal size, implying $n=0.5$. Initial income tax rate is set at $1-\tau_{0}^{I}=0.2$, implying $\tau_{0}^{I}=0.8$. Initial consumption tax rate is equal at $1-\tau_{0}^{C}=0.08$, implying $\tau_{0}^{C}=0.92$. Initial nominal wage $w_{0}$ is normalized to 1 , combining $\theta=11$ with equation (10) implies that

$P_{0}=p_{0}(z)=1.1$. Equation (12) implies that in the initial steady-state the following equation holds:

$$
N R C_{0}=\left(1-\tau_{0}^{I}\right) w_{0} l_{0}+\left(1-\tau_{0}^{C}\right) P_{0} C_{0}=\left(\left(1-\tau_{0}^{I}\right) w_{0}+\left(1-\tau_{0}^{C}\right) P_{0}\right) l_{0}
$$

We can therefore present the portion of initial income taxation on total taxations as

$$
u \equiv \frac{\left(1-\tau_{0}^{I}\right) w_{0} l_{0}}{N R C_{0}}=\frac{\left(1-\tau_{0}^{I}\right) w_{0}}{\left(1-\tau_{0}^{I}\right) w_{0}+\left(1-\tau_{0}^{C}\right) P_{0}}
$$

We get $\mathrm{u}=0.7$ after substituting out of parameters calibrated and into equation above.

Furthermore, we easily find $\overparen{N R C}=-1.99 \hat{\tau}^{C}$ and $\widehat{N R C}=-0.64 \hat{\tau}^{C}$. A 1 percent reduction in consumption tax rate has resulted in 1.99 percentage increases in nominal revenue collection in the short run as well as 0.64 percentage decreases in the long-run steady state. The results are clearly contrary to their numerical simulation exercise where cut in consumption tax decreases nominal revenue for government budget.

\subsection{Real Revenue Collection (RRC)}

An advantage of NOEM paradigm is monetary model with nominal rigidity, so we can analyze the response of tax reform to not only nominal revenue collection but also real resources available to government - that is real revenue collection (RRC), under the same framework. We can similarly define RRC abstracting from impact of price index on tax revenue.

$$
\begin{aligned}
& \overparen{R R C}=u\left(\hat{\tau}^{I}+\tilde{w}+\tilde{l}-\tilde{P}\right)+(1-u)\left(\hat{\tau}^{C}+\tilde{C}\right) \\
& \widehat{R R C}=u\left(\hat{\tau}^{I}+\hat{w}+\hat{l}-\hat{P}\right)+(1-u)\left(\hat{\tau}^{C}+\hat{C}\right)
\end{aligned}
$$

Equations ((40) and (41)) refer to real revenue collection in the short-run and long-run respectively. Using the fact above that $\hat{\tau}^{I}=0, \tilde{w}=0, \tilde{l}=\tilde{y}$, $\tilde{P}=(1-n) \tilde{e}, \hat{w}=\hat{P}, \hat{l}=\hat{y}$, we can derive the following reduced form for $\overparen{R R C}$ and $\widehat{R R C}$ :

$$
\begin{gathered}
\overparen{R R C}=u(\tilde{y}-(1-n) \tilde{e})+(1-u)\left(\hat{\tau}^{C}+\tilde{C}\right) \\
\widehat{R R C}=u \hat{y}+(1-u)\left(\hat{\tau}^{C}+\hat{C}\right)
\end{gathered}
$$

In the spirit of solving Equations ((38) and (39)), we can derive $\widetilde{R R C}$ and $\widehat{R R C}$ expressions which is a function of only $\hat{\tau}^{C}$. In analogy with NRC, it is 
not straightforward to tell coefficient signs in both RRC equations being functions of only $\hat{\tau}^{C}$ after substituting Equations ((31) to (35) into (42) and (43)), so we still resort to numerical solutions using calibrated parameters above. This yields $\overparen{R R C}=-1.77 \hat{\tau}^{C}$ and $\widehat{R R C}=-0.17 \hat{\tau}^{C}$, where this numerical results are quantitatively similar to NRC above but is opposed to Ganelli and Tervala [7], in the sense that a cut in domestic consumption tax rate increases total real revenue collection of government analogously. In order to confirm the robustness of our results, we outline some sensitivity analysis to negative real budgetary consequences. In particular, we observe how $\overparen{R R C}$ and $\widehat{R R C}$ changes when we change either the elasticity of substitution between differentiated goods $\theta$ or scale of domestic country $\mathrm{n}$. The results as well as previous outcome are reported in Table 3

From Table 3 we can easily know that our sensitivity analysis strengthens the robustness of the results.

We conclude that in our model not only nominal revenue collection is increase, but also real revenue collection increases in the presentation of a permanent reduction in domestic consumption tax rate. This implies that following a reduction in consumption tax rate today will be higher at some point in the future, is satisfied. This also means that dynamic Laffer effects emerge in our model. Our exercise in this section is analogous in spirit to the one carried out by Ganelli and Tervala [7] under NOEM paradigm, but the results we derive is completely different from their experiment.

\section{Conclusions}

What are the implications of consumption tax reform for macroeconomic and government budgetary consequences in open economies? The model presented in this paper extends OR model to incorporate consumption tax so as to analyze this question. Consumption unilateral tax rate reduction yields a economic boom, since increases consumption and output not only in the short run but also in the long run, makes the currency depreciate for the country which implement it. The main result of our analysis is that this policy constitutes dynamic Laffer Curve, in the sense that it has positive budgetary consequence for the country which implements it.

From the perspective of literature, our results are opposed to the result from Ganelli and Tervala [7]. Moreover, we solve our model by deriving analytical

Table 3. Reports sensitivity analysis.

\begin{tabular}{lccccc}
\hline & $\theta=11, n=0.5$ & $\theta=6$ & $\theta=2.5$ & $\mathrm{n}=0.2$ & $\mathrm{n}=0.8$ \\
\hline$\widetilde{N R R}$ & -1.99 & -1.42 & -0.94 & -1.08 & -0.8 \\
$\widehat{N R C}$ & -0.64 & -0.68 & -0.75 & -0.78 & -0.72 \\
$\overparen{R R C}$ & -1.77 & -1.17 & -0.60 & -0.54 & -0.66 \\
$\widehat{R R C}$ & -0.17 & -0.18 & -0.17 & -0.15 & -0.19 \\
\hline
\end{tabular}

Note: We switch one parameter while keeping another parameter unchanged. 
solutions, applying a simple graphical apparatus and using numerical solutions to penetrate dynamic Laffer curve, rather than using numerical simulations in their paper. It is reasonable for us that our method provides some virtues. In particular, the simple graphical apparatus that we discuss is benefit in presenting an intuitive explanation for the results how the policy of a reduction in domestic consumption tax rate impact main macroeconomic variables. Furthermore, deriving analytical solutions also allows us to study both total nominal and real revenue collection for government.

The conclusion of this study should be interpreted with caution, since the results are not consistent using different model. Further studies, especially empirical evidence, are needed to find the reasons of the conflict. An interesting extension of our model for future research could be integrating overlapping generation structure of the Blanchard type in NOEM paradigm which government debt can have real effects [10] with consumption tax. For example, studying how consumption tax reform affects macroeconomic variables in finite horizons for agents under the NOEM paradigm would also be of interest.

\section{References}

[1] Ireland, P. (1994) Supply-Side Economics and Endogenous Growth. Journal of Monetary Economics, 33, 559-571. https://doi.org/10.1016/0304-3932(94)90043-4

[2] Mendoza, E.G., Gian Maria Milesi, F. and Patrick, A. (1997) On the Ineffectiveness of Tax Policy in Altering Long-Run Growth: Harberger's Super Neutrality Conjecture. Journal of Public Economics, 66, 99-126. https://doi.org/10.1016/s0047-2727(97)00011-x

[3] Novales, A. and Jesus, R. (2002) Dynamic Laffer Curves. Journal of Economic Dynamics and Control, 27, 181-206. https://doi.org/10.1016/S0165-1889(01)00031-8

[4] Bruce, N. and Stephen, J.T. (1999) Budget Balance, Welfare, and the Growth Rate: "Dynamic Scoring" of the Long-Run Government Budget. Journal of Money, Credit and Banking, 31, 162-186. https://doi.org/10.2307/2601228

[5] Mankiw, N.G. and Matthew, W. (2006) Dynamic Scoring: A Back-of-the-Envelope Guide. Journal of Public Economics, 90, 1415-1433. https://doi.org/10.1016/j.jpubeco.2005.11.006

[6] Trabandt, M. and Harald, U. (2006) How Far Are We from the Slippery Slope? The Laffer Curve Revisited. CEPR Discussion Paper No. 5657.

[7] Ganelli, G. and Tervala, J. (2008) Tax Reforms, "Free Lunches”, and "Cheap Lunches" in Open Economies. IMF Working Papers, WP/08/227.

[8] Obstfeld, M. and Rogoff, K. (1995) Exchange Rate Dynamics Redux. Journal of Political Economy, 103, 624-660. https://doi.org/10.1086/261997

[9] Obstfeld, M. and Rogoff, K. (1996) Foundations of International Macroeconomics. MIT Press, Cambridge.

[10] Ganelli, G. (2005) The New Open Economy Macroeconomics of Government Debt. Journal of International Economics, 65, 167-184. https://doi.org/10.1016/j.jinteco.2004.03.001

[11] Ganelli, G. (2008) Public Spending Management and Macroeconomic Interdependence. Open Economies Review, 19, 241-259.

https://doi.org/10.1007/s11079-007-9018-8 


\section{Abbreviations}

OR: Obstfeld and Rogoff [8] develop redux model J Polit Eco;

NOEM: New Open Economy Macroeconomics;

NRC: Nominal Revenue Collection;

RRC: Real Revenue Collection

Submit or recommend next manuscript to SCIRP and we will provide best service for you:

Accepting pre-submission inquiries through Email, Facebook, LinkedIn, Twitter, etc. A wide selection of journals (inclusive of 9 subjects, more than 200 journals) Providing 24-hour high-quality service User-friendly online submission system Fair and swift peer-review system Efficient typesetting and proofreading procedure Display of the result of downloads and visits, as well as the number of cited articles Maximum dissemination of your research work

Submit your manuscript at: http://papersubmission.scirp.org/ Or contact tel@scirp.org 